\title{
Asthma related hospital treatment in Finland: 1972-86
}

\author{
Timo Keistinen, Tuula Tuuponen, Sirkka-Liisa Kivelä
}

\begin{abstract}
Background The number of asthma related treatment periods in hospital has increased in many countries, particularly among children. The aim of the present investigation was to describe the use made of hospital services by asthmatic patients over a wide range in Finland.
\end{abstract}

Methods A total of 255387 treatment periods for asthma that had occurred between 1972 and 1986 was collected from the discharge register maintained by the National Board of Health (diagnosis 493, International Classification of Diseases). The numbers of admissions, days in hospital, and new occurrences of asthma were calculated by sex and age in relation to the total population at the end of each year.

Results Asthma induced treatment periods in hospital in Finland were 12860 (277 treatment periods per 100000 inhabitants) in 1972 and 20000 (406 per 100000 inhabitants) in 1986. The annual increase in the number of such periods was $4.7 \%$ for men $(95 \%$ confidence interval (95\% CI) 3.5 to $5.9 \%$ ) and $3.4 \%$ for women $(2 \cdot 1$ to $4 \cdot 7 \%)$ in relation to population. The most pronounced change was found in those aged 65 years and over, in which the number of treatment periods was found to increase annually by $7 \cdot 5 \%$ $(6.0$ to $9.0 \%)$ for men and $4.9 \%(3.4$ to $6.5 \%$ ) for women, whereas the smallest increase was found among persons under 15 years with an annual change of $1.3 \%$ $(0 \cdot 2$ to $2 \cdot 3 \%)$ for boys and $1 \cdot 1 \%(-0 \cdot 1$ to $\mathbf{2} \cdot \mathbf{4} \%$ ) for girls. Although the number of asthma related treatment periods increased, that of new patients with asthma did not. An average of 114 new male asthmatic patients per 100000 men were treated in hospitals annually between 1977 and 1986, whereas the figure for women was 115; the annual change during this 10 year period was $0.2 \%(-0.8$ to $1 \cdot 2 \%)$ for men and $-0.8 \%(-1.8$ to $0.2 \%)$ for women.

Conclusions The increase in the number of asthma related hospital treatment periods seemed attributable to the frequent treatment of the same patients. Treatment periods for persons aged $\mathbf{4 0}$ years or over were found to increase most, suggesting that the treatment of these asthmatic patients should be optimised and its organisation improved.

(Thorax 1993;48:44-47)
The prevalence of asthma has been reported to have increased throughout the world, particularly among children and young people. ${ }^{1-3}$ The number of asthma related visits to general practitioners is considerable and is increasing, ${ }^{45}$ with consultations among children and the older age groups being most frequent. The number of periods of hospital treatment has also increased worldwide, particularly among children under five years of age; the rise has been less prominent in older age groups. ${ }^{6-10}$ The factors contributing to such an increase in the number of treatment periods are still unclear, although some investigations have suggested that it is attributable to new patients with asthma seeking hospital treatment. ${ }^{9}$

The prevalence of asthma among young men in Finland is reported to have increased 20 fold between the early 1960 s and the late $1980 \mathrm{~s}^{2}$ The National Board of Health maintains a register of all patients discharged from hospital since 1967, which is extended by about one million new entries annually, so that it now contains data on roughly 20 million treatment periods. This provides a good basis for studying trends in asthma related hospital treatment. The aim of the present investigation is to describe the use made of hospital services by asthmatic patients of different ages in Finland and to identify groups with special treatment needs.

\section{Material and methods}

The National Board of Health is provided with registration data on all patients treated in hospital in Finland, including their diagnoses. All treatment periods for which the main diagnosis was asthma were collected from the register (diagnosis 493, International Classification of Diseases (ICD), eighth revision), including acute exacerbation stages, diagnostic examinations, and check up visits. A total of 255387 asthma related treatment periods were recorded between 1972 and 1986, and the numbers of admissions, days spent in hospital, and new occurrences of asthma were calculated by sex and age in relation to the total population at the end of each year.

All hospital treatment days were counted as days in hospital, the days of arrival and departure making up one day. If the duration of treatment exceeded 365 days, these days were excluded from the analysis. An average of less than 15 treatment periods of such duration occurred annually, and they were usually for elderly people receiving long term inpatient care. The average duration of stay in hospital 


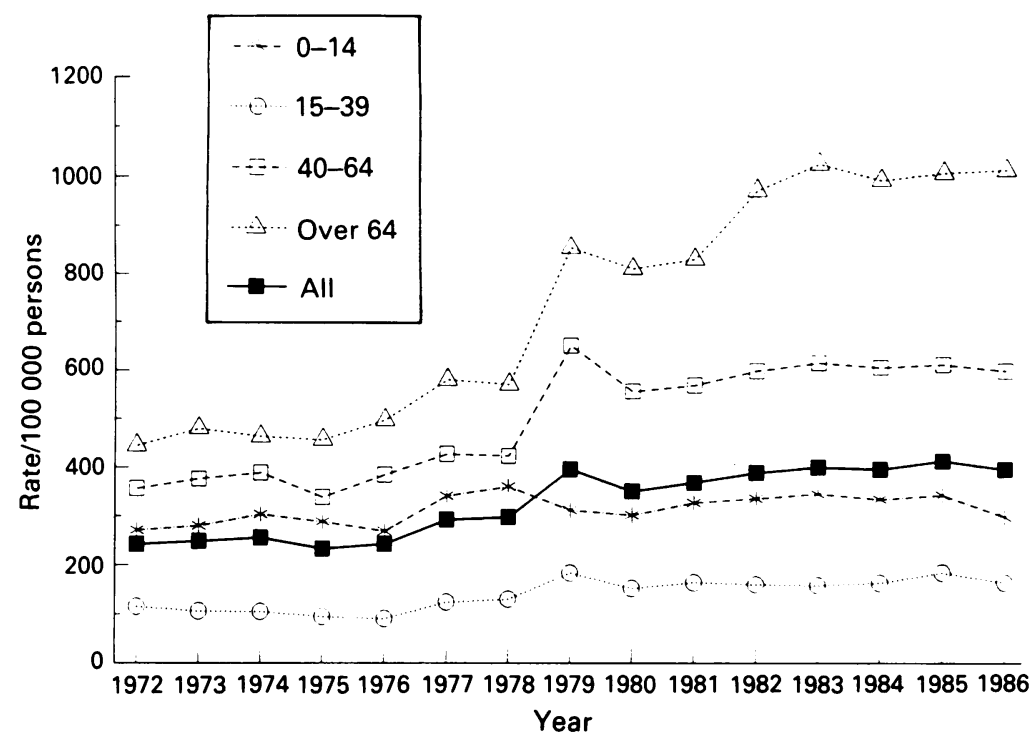

Figure 1 Asthma related rates of admission to hospital per 100000 persons for men from 1972 to 1986.

was calculated by dividing the number of days in hospital by the number of treatment periods.

An asthmatic patient who had had no recorded asthma related hospital treatment periods between 1972 and 1976 and was first treated in hospital in 1977 or later was considered as a new patient.

The register files were processed by computer at the Department of Public Health Science and General Practice, University of Oulu. The population data were based on information provided by the Central Statistical Office of Finland.

Trends were analysed by one of two methods. Linear regression was performed on the rate of admissions to hospital per 100000 population per year to determine the absolute rate of change, and the relative rate of change was calculated by linear regression on the natural logarithm of the rate of hospital admission. ${ }^{11}$ The percentage change per year is equivalent to $\mathrm{e}^{\beta}-1$. Hospital admissions, days

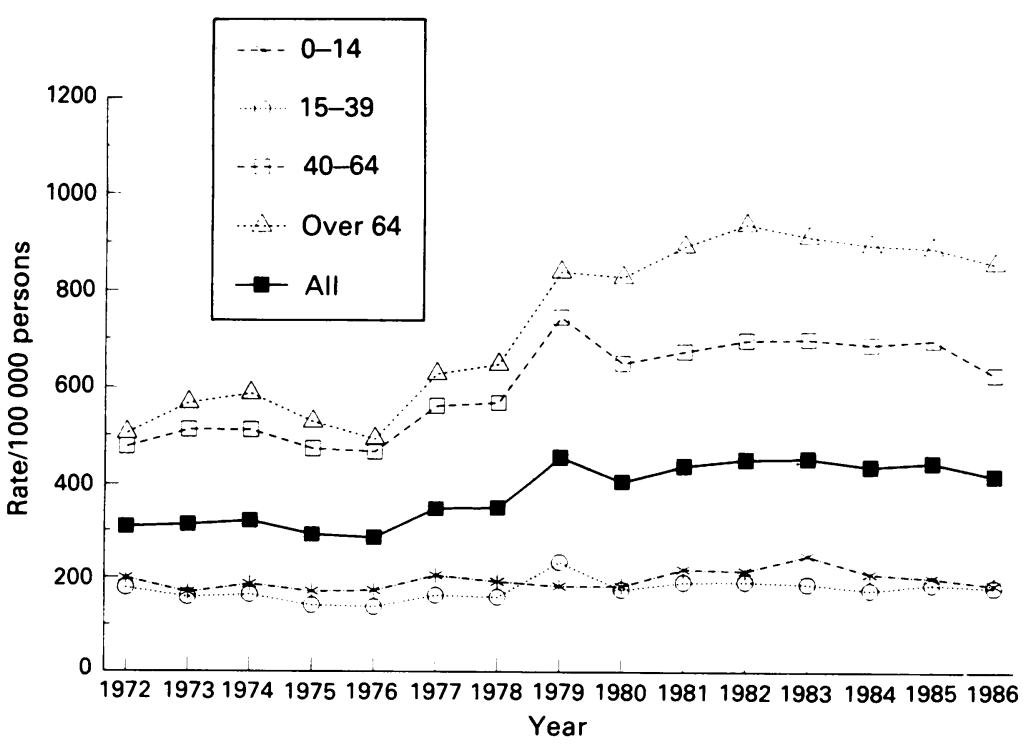

Figure 2 Asthma related rates of admission to hospital per 100000 persons for women from 1972 to 1986. hospital, and new asthmatic patients were evaluated separately by sex with a two sample $t$ test. The statistical analyses were performed with the SOLO program of BMDP Statistical Software Inc.

\section{Results \\ TREATMENT PERIODS}

There was a total of 12860 asthma related treatment periods in Finland in 1972 (277 per 100000 inhabitants). The number then increased considerably over 15 years, amounting to 20000 in 1986 (406 per 100000 inhabitants; figs 1 and 2). The highest numbers were found for both sexes in the age groups 40 years and over (table 1), whose asthma related treatment periods increased most rapidly during the 15 year period.

The number of treatment periods was greater among boys younger than 15 years than among girls of the same age $(p<0.0001)$, whereas the number of such periods among young female adults (age range 15-39 years) and older women of working age (age range 4064 years) was greater than among the men of the same age range $(p<0.005$ and $p<0.05)$. The number of treatment periods was similar among men and women aged 65 years or over.

\section{DAYS IN HOSPITAL AND AVERAGE DURATION OF} STAY IN HOSPITAL

The number of asthma related days in hospital was 3188 per 100000 inhabitants in 1972 and 2679 per 100000 inhabitants in 1986-that is, there was an annual change of $+0.03 \%(95 \%$ confidence interval ( $95 \% \mathrm{CI})-1.3$ to $1.4 \%$ ). When compared with the number of persons in a given age group, the annual change in the number of hospital days was $-3 \cdot 1 \%(-4 \cdot 1$ to $-2 \cdot 1 \%$ ) among persons under 15 years of age, $-2.6 \%(-4.4$ to $-0.7 \%)$ among young adults, $-1 \cdot 1 \%(-2 \cdot 8$ to $0.5 \%)$ among older people of working age, and $2.3 \%(1.0$ to $3.8 \%)$ among persons of age 65 years or over.

The average duration of stay in hospital reduced during the 15 years, from 11.5 days in 1972 to 6.6 days in 1986 . The average stay in hospital for the older age groups was longer than that for the younger asthmatics patients, but no differences were found between the sexes in this respect.

\section{NEW ASTHMA PATIENTS}

The number of new asthma cases among men and women remained practically unchanged between 1977 and 1986 (table 2). Most of the new cases in the men occurred among boys and in the age group 65 years and over, and those among the women in the age group 40 years and over.

There were no differences in the total number of new asthma cases between the men and women in the entire population, although new occurrences were more often found among boys under 15 years than among girls of the same age $(p<0.0001)$. No significant sex related differences were found among young adults, but new cases occurred more often among older women of working age than 
Table 1 Change in asthma related rate of admission to hospital among Finnish men and women per 100000 persons from 1972 to 1986

\begin{tabular}{|c|c|c|c|}
\hline Age & $\begin{array}{l}\text { Mean (SD) rate of } \\
\text { admissions }\end{array}$ & $\begin{array}{l}\text { Absolute }(95 \% \mathrm{CI}) \\
\text { rate of change } \\
\text { per } 100000 \\
\text { population/year }\end{array}$ & $\begin{array}{l}\text { Average \% }(95 \% C I) \\
\text { change/year }\end{array}$ \\
\hline \begin{tabular}{l}
\multicolumn{1}{c}{$0-14$} \\
$15-39$ \\
$40-64$ \\
Over 64 \\
All
\end{tabular} & $\begin{array}{l}314(29 \cdot 4) \\
140(32 \cdot 1) \\
500(115 \cdot 0) \\
732(237 \cdot 4) \\
328(70 \cdot 5)\end{array}$ & $\begin{array}{l}\text { Men } \\
3.8(0.6 \text { to } 7.0) \\
6.0(3.6 \text { to } 8.4) \\
22.7(15.4 \text { to } 30.0) \\
50.6(41.0 \text { to } 60.2) \\
14.5(10.9 \text { to } 18.2)\end{array}$ & $\begin{array}{l}1.3(0.2 \text { to } 2.3) \\
4.6(2.7 \text { to } 6.5) \\
4.9(3.3 \text { to } 6.4) \\
7.5(6.0 \text { to } 9.0) \\
4.7(3.5 \text { to } 5.9)\end{array}$ \\
\hline $\begin{array}{l}0-14 \\
15-39 \\
40-64 \\
\text { Over } 64 \\
\text { All }\end{array}$ & $\begin{array}{l}195(20 \cdot 9) \\
174(23 \cdot 0) \\
601(97 \cdot 0) \\
732(169 \cdot 2) \\
380(65 \cdot 1)\end{array}$ & $\begin{array}{l}\text { Women } \\
2 \cdot 2(-0.2 \text { to } 4 \cdot 7) \\
2 \cdot 2(-0.6 \text { to } 5 \cdot 0) \\
17 \cdot 5(9 \cdot 8 \text { to } 25 \cdot 2) \\
33 \cdot 8(23 \cdot 6 \text { to } 44 \cdot 0) \\
12.4(7 \cdot 7 \text { to } 17 \cdot 0)\end{array}$ & $\begin{array}{l}1.1(-0.1 \text { to } 2.4) \\
1.3(-0.2 \text { to } 2.9) \\
3.1(1.8 \text { to } 4.4) \\
4.9(3.4 \text { to } 6.5) \\
3.4(2.1 \text { to } 4.7)\end{array}$ \\
\hline
\end{tabular}

among men of the same age ( $p<0.0001)$. New asthma diagnoses proved to be more common among men aged 65 or over than among women of the same age $(\mathrm{p}<0.05)$.

\section{Discussion}

The discharge register maintained by the National Board of Health is an extensive one as it covers all private, public, general, and mental hospitals in Finland. The correspondence between its diagnosis data and patient records has been found to be good, even as high as $95 \% .^{12}$ The same classification of diseases has been used in Finland throughout the period concerned (ICD, 8th revision), which means that the increase in asthma related hospital admissions cannot be attributable to any changes in classification. It is unlikely that an appreciable change has taken place in the diagnostic practices employed in Finland during this period, as the grounds upon which the National Insurance Fund awarded free medicines for asthma remained unchanged until the end of 1985.

The number of asthma related hospital admissions is determined by several factors. A decision on whether a person at the exacerbation stage of asthma should be admitted to hospital is usually made in the emergency department largely on the basis of the clinical picture. ${ }^{13}$ Easy availability of hospital services may lead to their increased use, as may the tendency for hospitals to utilise all their available beds. These are some of the factors which may cause unnecessary use of hospital services. $^{14}$

Table 2 Occurrences of new asthma cases among Finnish men and women per 100000 persons from 1977 to 1986

\begin{tabular}{|c|c|c|c|}
\hline Age & $\begin{array}{l}\text { Mean ( } S D \text { ) new } \\
\text { asthma cases }\end{array}$ & $\begin{array}{l}\text { Absolute }(95 \% \text { CI) } \\
\text { rate of change } \\
\text { per } 100000 \\
\text { population/year }\end{array}$ & $\begin{array}{l}\text { Average \% }(95 \% \mathrm{CI}) \\
\text { changelyear }\end{array}$ \\
\hline $\begin{array}{l}0-14 \\
15-39 \\
40-64 \\
>64 \\
\text { All }\end{array}$ & $\begin{array}{l}130(15 \cdot 8) \\
70(4 \cdot 9) \\
151(7 \cdot 7) \\
176(21 \cdot 0) \\
114(4 \cdot 3)\end{array}$ & $\begin{array}{l}\text { Men } \\
-3.0(-6.5 \text { to } 0.6) \\
0.4(-0.9 \text { to } 1.7) \\
0.2(-1.9 \text { to } 2.3) \\
5.8(2.7 \text { to } 8.9) \\
0.2(-0.9 \text { to } 1.4)\end{array}$ & $\begin{array}{l}-2.2(-4.8 \text { to } 0.5) \\
+0.5(-1.3 \text { to } 2.3) \\
+0.1(-1.3 \text { to } 1.6) \\
+3.4(1.5 \text { to } 5.3) \\
+0.2(-0.8 \text { to } 1.2)\end{array}$ \\
\hline $\begin{array}{l}0-14 \\
15-39 \\
40-64 \\
>64 \\
\text { All }\end{array}$ & $\begin{array}{r}78(8 \cdot 4) \\
72(4 \cdot 3) \\
176(9 \cdot 5) \\
157(6 \cdot 2) \\
115(5 \cdot 0)\end{array}$ & $\begin{array}{l}\text { Women } \\
-1.6(-3.4 \text { to } 0.3) \\
-0.6(-1.7 \text { to } 0.5) \\
-2.4(-4.0 \text { to }-0.7) \\
0.4(-1.3 \text { to } 2.0) \\
-0.9(-2.1 \text { to } 0.2)\end{array}$ & $\begin{array}{l}-2.0(-4.3 \text { to } 0.3) \\
-0.9(-2.4 \text { to } 0.6) \\
-1.4(-2.3 \text { to }-0.4) \\
+0.3(-0.8 \text { to } 1.3) \\
-0.8(-1.8 \text { to } 0.2)\end{array}$ \\
\hline
\end{tabular}

The number of asthma related admissions to hospital in Finland was found to have increased, the most prominent increase being among older working age persons and those aged 65 years or over. Earlier investigations have reported an increase in the number of treatment periods among children, ${ }^{6-1015}$ but few reports have been published on older age groups. ${ }^{7}$ In our present investigation the treatment periods of Finnish children were found to correspond with those of the children of the United Kingdom, ${ }^{915}$ and those of the United States, ${ }^{10}$ but were less than those reported among Canadian ${ }^{78}$ and New Zealand children. ${ }^{615}$ The number of periods in hospital was considerable among the adults, however. The number of days in hospital in this study has been found to increase among the elderly, who have multiple illnesses, including chronic ones that involve psychosocial problems. This may lead to an increased use of hospital services. ${ }^{16} 17$ The changes in the numbers of new asthmatic patients do not account for the increases in the figures for treatment periods, but rather the same patients use hospital services repeatedly. The repeated periods in hospital may have shortened the average treatment time, which is a sign of active nursing practice.

In international terms, the Finnish health care system is characterised by a large number of beds available relative to the population size. Despite the emphasis on hospital treatment, a serious attempt has been made to develop outpatient services. The number of doctors in Finland almost doubled during the period considered here, the new posts being mainly in primary health care. There was an increase in numbers of new doctors in the late 1970s because two medical schools were established in 1972. The increase in the number of general practitioners, the easier admission to hospitals, and the greater expectations of patients may also have led to an increased use of hospital services in Finland, ${ }^{18}$ resulting in turn in a change in the admittance criteria. General practitioners differ in terms of the criteria on which they refer a patient to hospital. ${ }^{15}$

Periods in hospital due to tuberculosis decreased in Finland in the 1970s, because of the decrease in the prevalence of tuberculosis and the introduction of new medication. This allowed alternative use of the increased resources for treating other pulmonary diseases. The increase in the number of cases of asthma found in 1979 may be partly attributable to the creation of a national treatment programme and the increased number of new doctors in the late $1970 \mathrm{~s} .{ }^{19}$ As the programme required the diagnosis of asthma by a specialist, the related diagnostic examinations may have been reflected as a rise in the number of periods in hospital. Improved diagnosis in the older age groups may have contributed to some of the patients suffering from chronic bronchitis and emphysema receiving hospital treatment for asthma in more recent times. Although asthma is a disease that is difficult to diagnose, the diagnoses in the present material can be regarded as fairly reliable as they are based on treatment periods involving the same patients 
and were made by a hospital physician.

An increase in the prevalence of asthma among young Finnish men has been reported to have taken place since the early $1960 \mathrm{~s}^{2}$ The use of medication for asthma has increased, as has the number of persons entitled to receive free asthma medicines through the National Insurance Fund. No increase has been found in mortality from asthma in Finland, and the number of asthma related deaths has decreased in some parts of the country. ${ }^{20}$

Although the numbers of periods in hospital required for the treatment of asthma have increased and the clinical picture of the disease may have become more problematic, the number of deaths may have been reduced by the improved access to treatment. It has been claimed that an active attitude among patients towards contacting an outpatient department in the event of an asthma attack is regarded as likely to reduce the number of related deaths. ${ }^{21}$

In summary, the number of asthma related treatment periods increased in Finland among older people of working age and the elderly in particular between 1972 and 1986. The rise in the number of treatment periods cannot be accounted for by new occurrences of asthma, but can be explained by the same asthmatic patients, especially those aged 40 years or older, seeking hospital treatment repeatedly. Special attention should thus be paid to improving the treatment organisation, enhancing the effectiveness of the treatment provided, and re-evaluating the use of resources.

1 Burney PGJ, Chinn S, Rona RJ. Has the prevalence of asthma increased in children? Evidence from the national study of health and growth 1973-86. BMJ 1990;300: 1306-10.

2 Haahtela T, Lindholm H, Björksten F, Koskenvuo K, Laitinen LA. Prevalence of asthma in Finnish young men. BMJ 1990;301:266-8.
3 Robertson CF, Heycock E, Bishop J, Nolan T, Olinsky A, Phelan PD. Prevalence of asthma in Melbourne schoolchildren: changes over 26 years. BMJ 1991:302:1116-8.

4 Pedersen PA, Weeke ER. Asthma in Danish general practice. Allergy 1981;36:175-81.

5 Fleming DM, Crombie DL. Prevalence of asthma and hay fever in England and Wales. BMJ 1987;297:279-83.

6 Mitchell EA. International trends in hospital admission rates for asthma. Arch Dis Child 1985;60:376-8.

7 Mao Y, Semenciw R, Morrison H, MacWilliam L, Davies J, Wigle $D$. Increased rates of illness and death from asthma in Canada. Can Med Assoc J 1987;137:620-4.

8 Infante-Rivard C, Sukia SE, Roberge D, Baumgarten M. The changing frequency of childhood asthma. $J$ Asthma 1987;24:283-8.

9 Anderson HR. Increase in hospital admissions for childhood asthma: trends in referral, severity, and readmissions from 1970 to 1985 in a health region of the United Kingdom. Thorax 1989;44:614-9.

10 Gergen PJ, Weiss KB. Changing patterns of asthma hospitalization among children: 1979 to 1987 . JAMA 1990; 264:1688-92.

11 Kleinman JC. State trends in infant mortality, 1968-83. Am $J$ Public Health 1986;76:681-7.

12 Aro S, Koskinen R, Keskimäki I. The correspondence of data about the diagnoses, operations and accidents in the hospital discharge register maintained by National Board of Health. Duodecim 1990;106:1443-50. (In Finnish.)

13 Kerem E, Tibshirani R, Canny G, Bentur L, Reisman J, Schuh S, et al. Predicting the need for hospitalization in children with acute asthma. Chest 1990;98:1355-61.

14 Anderson P, Meara J, Brodhurst S, Attwood S, Timbrell M, Gatherer A. Use of hospital beds: a cohort study of admissions to a provincial teaching hospital. $B M J 1988$; 297:910-2.

15 Mitchell EA, Anderson HR, Freeling P, White PT. Why are hospital admission and mortality rates for childhood asthma higher in New Zealand than in the United Kingdom? Thorax 1990;45:176-82.

16 Kaptein AA. A Psychological correlates of length of hospitalization and rehospitalization in patients with acute, severe asthma. Soc Sci Med 1982;16:725-9.

17 Andrén KG, Rosenqvist U. Heavy users of an emergency department-a two year follow-up study. Soc Sci Med 1987;25:825-31.

18 Durojaiye LIA, Hutchison T, Madeley RJ. Improved primary care does not prevent the admission of children to hospital. Public Health 1989;103:181-8.

19 Kokkola K, Finell B, Lahdensuo A. Regional implementation of a medical care programme in Northern Finland. Community Medicine 1983;5:109-15.

20 Kinnula V, Nurmela T, Liippo K, Tala E, Huhti E. Fatal asthma in two regions of Finland. Annals of Clinical Research 1988;20:189-94.

21 Crompton GK, Grant IWB, Chapman BJ, Thomson A, McDonald CF. Edinburgh emergency asthma admission service: report on 15 years' experience. European Journal of Respiratory Diseases 1987;70:266-71. 